\title{
Degree of Resection and Ki-67 Labeling Index for Recurring Meningiomas
}

\author{
Richard Menger ${ }^{1}$, David E. Connor Jr. ${ }^{1}$, Alvin Y. Chan ${ }^{2}$, Gary Jain ${ }^{3}$, Anil Nanda ${ }^{1}$ \\ 1. Department of Neurosurgery, LSU Health Sciences Center Shreveport 2. Medical College of Wisconsin 3. Department \\ of Surgery, University of Illinois Mt. Sinai
}

Corresponding author: Alvin Y. Chan, alvinyhchan@gmail.com

\begin{abstract}
Objective

Meningioma recurrence after resection is likely influenced by multiple surgical and histologic factors. In this study, the degree of resection and tumor immunoreactivity to MIB-1 (i.e., Ki-67 labeling index (LI)) are described in recurrent and non-recurrent meningioma cases.
\end{abstract}

Methods

Data regarding tumor location, the degree of resection, histologic features, and the degree of Ki-67 positivity were collected for 32 patients treated between September 2008 and July 2009. Follow-up for recurrence was assessed through five years.

Results

A total of 32 patients ( 13 males; 19 females) underwent resection. The mean age was 53.3 years. Gross total resection (GTR) occurred in 25 (78.1\%) cases. Near-total resection (NTR) occurred in five (15.6\%) cases. Subtotal resection (STR) occurred in two (6.2\%) cases. The overall mean Ki-67 LI score was 9.75\% (ranging between $1 \%$ to $48 \%$ ). The mean Ki-67 LI for GTR, NTR, and STR cases were $8.0 \%, 10.2 \%$, and $29.5 \%$ respectively. Tumor recurrence occurred in five (15.6\%) patients. The mean Ki-67 LI for recurrence lesions was $22.2 \%$.

Conclusion

We present our descriptive data for Ki-67 LI for initial tumors and recurrence. The risk of recurrence following resection of meningiomas may be associated with the degree of Ki-67 positivity.

Received 06/16/2017

Review began 06/29/2017

Review ended 11/01/2017

Published 11/03/2017

๑) Copyright 2017

Menger et al. This is an open access article distributed under the terms of the Creative Commons Attribution License CC-BY 3.0., which permits unrestricted use, distribution, and reproduction in any medium, provided the original author and source are credited.
Categories: Neurosurgery, Oncology

Keywords: meningioma, ki-67 labeling index, recurrence

\section{Introduction}

The published rates of recurrence following resection of intracranial meningiomas range between $2 \%$ to $80 \%$ [1-12]. The factors affecting the incidence of recurrence have traditionally focused on operative variables, such as the degree of resection, age, and gender $[1,6,13]$. For example, Simpson established a grading system for the degree of resection and correlated each grade to a relative recurrence risk [9]. Thus, theoretically, certain histopathological and anatomical variations lead to a higher probability of recurrence. There is some evidence that the Ki-67 protein, a proliferative marker, could be an accurate predictor of recurrence, though the data is not conclusive [2].

We present our institution's (Louisiana State University in Shreveport, Louisiana) data for the immunoreactivity to MIB-1 or Ki-67 labeling index (LI) for the recurrence of meningioma. We also provide a brief review of the literature.

\section{Materials And Methods}

The data for 32 patients who were operated on at our institution between September 2008 to July 2009 for intracranial or intraspinal meningioma were reviewed and then subsequently followed for five years. Patient charts, laboratory records, and radiographic imaging were analyzed. Data regarding the clinical course, recurrence rates, and the need for revision were collected over a five-year follow-up period. The original formalin-preserved specimens were obtained for computer-assisted quantitative immunohistochemical analysis. 


\section{Cureus}

The specimens were reviewed to determine the histologic World Health Organization (WHO) grade, the presence of cellular pleomorphism or tumor necrosis, progesterone receptor (PR) positivity, and immunoreactivity to MIB-1. For each case, formalin-fixed and paraffin-embedded specimens were sectioned at $4 \mu \mathrm{m}$ and processed in an automated stainer, Ventana XT (Ventana Medical Systems, Tucson, AZ, USA), where deparaffinization and mild antigen retrieval occurred. The specimens were incubated with Ki-67 (clone 30-9) for 24 minutes. Biotinylated secondary antibodies were detected using the streptavidin/horseradish peroxidase method with diaminobenzidine as the chromogen. The slides were washed with ultraWash and hematoxylin counterstained. The percentage of immunopositive tumor cell nuclei was determined from digital images at 40x high power field (HPF) in the highest labeling regions of each case using an Automated Cellular Imaging System (ACIS) (ChromaVision Medical Systems, Inc., San Juan Capistrano, CA, USA).

Pre- and postoperative contrast-enhanced images were reviewed to identify the location and assess the resection degree. The grading was gross total resection (GTR) when there was no clear residual, near-total resection (NTR) when there was very minimal residual contrast-enhancement (including dural enhancement), and subtotal resection (STR) when there was substantial residual.

\section{Results}

There were 13 males (40.6\%) and 19 females (59.4\%). The mean age at presentation was 53.3 years (ranging between 17-83). The majority of resected lesions were supratentorial, with the most common locations occurring in the anterior skull base (28.1\%) and in proximity to the sagittal sinus (21.9\%). The anatomic location is summarized in Table 1 .

\begin{tabular}{|ll}
\hline Location & Patient (Pe \\
\hline Anterior Skull Base & $9(28.1 \%)$ \\
\hline Parasagittal & $7(21.9 \%)$ \\
Convexity & $6(18.8 \%)$ \\
\hline Petroclival & $3(9.4 \%)$ \\
\hline Posterior Fossa & $2(6.3 \%)$ \\
Sphenoid Wing & $2(6.3 \%)$ \\
Cavernous Sinus & $1(3.1 \%)$ \\
Thoracic & $1(3.1 \%)$ \\
Cervical & $1(3.1 \%)$ \\
Total & $32(100 \%)$
\end{tabular}

\section{TABLE 1: Distribution of resected meningiomas by anatomic location}

The pathology evaluation and the mean Ki-67 LI values are summarized in Table 2.

\begin{tabular}{|c|c|c|c|}
\hline & WHO Grade & Patients & Mean LI \\
\hline \multirow{3}{*}{ Primary Tumors } & 1 & 29 & 8.0 \\
\hline & II & 3 & 27.0 \\
\hline & III & 0 & - \\
\hline \multirow{2}{*}{ Recurrence } & 1 & 4 & 21.2 \\
\hline & II & 1 & 26.0 \\
\hline index (LI) & meringivi & Cograue & Oा nI-0 \\
\hline
\end{tabular}


Grade I lesion variants included 21 syncytial, three psammomatous, two translational, two cellular, and one microcystic meningiomas. Grade II lesions included two atypical and one clear cell meningioma. Tumor recurrence was identified to occur in five patients, four of whom required subsequent operative intervention. Recurrences were identified at a median of 34.1 months after initial resection. The mean Ki-67 LI for the initial resection samples of tumors that recurred was $22.2 \%$ (ranging between $11 \%$ to $48 \%$ ) with a mean PR positivity of $52.4 \%$ (ranging between $0 \%$ to $92 \%$ ). The degree of resection and the mean Ki-67 LI are summarized in Table 3.

\begin{tabular}{|c|c|c|}
\hline Degree of Resection & Patient Number & Ki-67 LI \\
\hline Gross Total Resection & 25 & 8.7 \\
\hline Near Total Resection & 5 & 7.0 \\
\hline Subtotal Resection & 2 & 29.5 \\
\hline
\end{tabular}

\section{Discussion}

We present our Ki-67 labeling index data for initial resection of meningioma and recurrence. Meningiomas represent $13 \%$ to $26 \%$ of primary intracranial neoplasms, with the majority classified as WHO grade I or benign [14]. The recurrence of completely resected benign meningiomas ranges from $7 \%$ to $32 \%$, increasing to $19 \%$ to $50 \%$ in higher Simpson grade resections $[1,4,9,15-16]$.

The proliferation markers associated with aggressive tumors in other organ systems (e.g., p53) have poor predictive value in meningiomas [17-22]. The MIB-1 monoclonal antibody recognizes Ki-67, a nuclear protein that is expressed during the G1, S, G2, and M phases of the cell cycles but absent in the G0 phase and early part of the G1 phase [23-25]. Consistent MIB-1 detection in tumor tissues makes it a better proliferation marker than proliferating cell nuclear antigen (PCNA) [26-27].

There is evidence that specific values of Ki-67 LI can help predict meningioma recurrence. Ki-67 LI is typically higher in recurrent tumors when compared to nonrecurrent tumors [2, 11, 27-29]. Kolles, et al. found Ki-67 LI to be a consistent factor for distinguishing anaplastic from benign meningiomas [29]. Bruna, et al. showed that Ki-67 LI was the only independent predictor of tumor recurrence and overall survival [2]. Perry, et al. showed that recurrence was more likely with a Ki-67 LI higher than or equal to 4.2\% in GTR [20]. A similar review of 83 patients with a 10-year follow-up identified a threshold Ki-67 LI value of 10\% [24]. Specifically, 30/31 patients with Ki-67 LI greater than or equal to 10\% developed a recurrent tumor within 10 years and $100 \%$ of patients with $\mathrm{Ki}-67 \mathrm{LI}$ lower than $10 \%$ were recurrence-free. Despite these results, laboratory differences in staining and counting methodologies make generalized application of a specific threshold difficult.

Several studies showed no correlation between Ki-67 LI and recurrence. In a review of 85 cases where $80 \%$ of the cases had recurrence, showed no significant difference in Ki-67 LI between the recurrent and nonrecurrent tumors [16]. A limitation was that regions within the specimens were chosen at random for Ki67 LI scoring. Abramovich, et al. recommended that the highest degree of positive staining should be used because it represents the proliferative potential [30]. In a review of 169 completely resected WHO grade I meningiomas, Roser, et al. found no significant difference in survival based on the mean Ki-67 LI [15]. Some believe that higher $\mathrm{Ki}-67 \mathrm{LI}$ in the case of higher grade tumors is more of a reflection of their anaplastic or malignant nature and that this testing should be reserved for cases with more borderline histologic features where classification and prognosis are more ambiguous [15, 19, 21, 30].

\section{Conclusions}

Here we presented our data for Ki-67 LI for initial meningiomas and recurrence up to five years. The risk of recurrence following resection of meningiomas may be associated with the degree of Ki-67 positivity but further research is required to conclusively determine the true relationship.

\section{Additional Information}

\section{Disclosures}

Human subjects: Consent was obtained by all participants in this study. Animal subjects: All authors have confirmed that this study did not involve animal subjects or tissue. Conflicts of interest: In compliance with the ICMJE uniform disclosure form, all authors declare the following: Payment/services info: All 
authors have declared that no financial support was received from any organization for the submitted work. Financial relationships: All authors have declared that they have no financial relationships at present or within the previous three years with any organizations that might have an interest in the submitted work.

Other relationships: All authors have declared that there are no other relationships or activities that could appear to have influenced the submitted work.

\section{References}

1. Adegbite AB, Khan MI, Paine KW, Tan LK: The recurrence of intracranial meningiomas after surgical treatment. J Neurosurg. 1983, 58:51-56.

2. Bruna J, Brell M, Ferrer I, Gimenez-Bonafe P, Tortosa A: Ki-67 proliferative index predicts clinical outcome in patients with atypical or anaplastic meningioma. Neuropathology. 2007, 27:114-120. 10.1111/j.14401789.2007.00750.x

3. Crompton MR, Gautier-Smith PC: The prediction of recurrence in meningiomas. J Neurol Neurosurg Psychiatry. 1970, 33:80-87. 10.1136/jnnp.33.1.80

4. Jääskeläinen J: Seemingly complete removal of histologically benign intracranial meningioma: late recurrence rate and factors predicting recurrence in 657 patients. A multivariate analysis. Surg Neurol. 1986, 26:461-469. 10.1016/0090-3019(86)90259-4

5. Jellinger K, Slowik F: Histological subtypes and prognostic problems in meningiomas . J Neurol. 1975, 208:279-298. 10.1007/BF00312803

6. Marks SM, Whitwell HL, Lye RH: Recurrence of meningiomas after operation. Surg Neurol. 1986, 25:436440. 10.1016/0090-3019(86)90081-9

7. Mirimanoff RO, Dosoretz DE, Linggood RM, Ojemann RG, Martuza RL: Meningioma: analysis of recurrence and progression following neurosurgical resection. J Neurosurg. 2010, 112:18-24.

8. Rohringer M, Sutherland GR, Louw DF, Sima AA: Incidence and clinicopathological features of meningioma . J Neurosurg. 1989, 71:665-672.

9. Simpson D: The recurrence of intracranial meningiomas after surgical treatment. J Neurol Neurosurg Psychiatr. 1957, 20:22-39. 10.1136/jnnp.20.1.22

10. Skullerud K, Löken AC: The prognosis in meningiomas. Acta Neuropathol. 1974, 29:337-344. 10.1007/BF00685486

11. Takeuchi H, Kubota T, Kabuto M, Kitai R, Nozaki J, Yamashita J: Prediction of recurrence in histologically benign meningiomas: proliferating cell nuclear antigen and Ki-67 immunohistochemical study. Surg Neurol. 1997, 48:501-506. 10.1016/S0090-3019(97)00235-8

12. Yamashita J, Handa H, Iwaki K, Abe M: Recurrence of intracranial meningiomas, with special reference to radiotherapy. Surg Neurol. 1980, 14:33-40.

13. Perry A, Stafford SL, Scheithauer BW, Suman VJ, Lohse CM: Meningioma grading: an analysis of histologic parameters. Am J Surg Pathol. 1997, 21:1455-1465.

14. Willis J, Smith C, Ironside JW, et al.: The accuracy of meningioma grading: a 10-year retrospective audit . Neuropathol Appl Neurobiol. 2004, 31:141-149.

15. Roser F, Samii M, Ostertag H, Bellinzona M: The Ki-67 proliferation antigen in meningiomas. experience in 600 cases. Acta Neurochir. 2004, 146:37-44. 10.1007/s00701-003-0173-4

16. Møller ML, Braendstrup O: No prediction of recurrence of meningiomas by PCNA and Ki-67 immunohistochemistry. J Neurooncol. 1997, 34:241-246. 10.1023/A:1005794700267

17. Cobb MA, Husain M, Andersen BJ, Al-Mefty O: Significance of proliferating cell nuclear antigen in predicting recurrence of intracranial meningioma. J Neurosurg. 1996, 84:85-90.

18. Nagashima G, Aoyagi M, Yamamoto M, et al.: P53 overexpression and proliferative potential in malignant meningiomas. Acta Neurochir. 1999, 141:53-61. 10.1007/s007010050266

19. Prayson RA: Malignant meningioma: a clinicopathologic study of 23 patients including MIB1 and p53 immunohistochemistry. Am J Clin Pathol. 1996, 105:719-726. 10.1093/ajcp/105.6.719

20. Perry A, Stafford SL, Scheithauer BW, Suman VI, Lohse CM: The prognostic significance of MIB-1, p53, and DNA flow cytometry in completely resected primary meningiomas. Cancer. 1998, 82:2262-2269. 10.1002/(SICI)1097-0142(19980601)82:11<2262::AID-CNCR23>3.0.CO;2-R

21. Terzi A, Saglam EA, Barak A, Soylemezoglu F: The significance of immunohistochemical expression of Ki67, p53, p21, and p16 in meningiomas tissue arrays. Pathol Res Pract. 2008, 204:305-314. 10.1016/j.prp.2008.01.013

22. Verheijen FM, Sprong M, Kloosterman JME, Blaauw G, Thijssen JHH, Blankenstein MA: TP53 mutations in human meningiomas. Int J Biol Markers. 2002, 17:42-48. 10.5301/JBM.2008.3174

23. Gerdes J, Schwab U, Lemke H, Stein H: Production of a mouse monoclonal antibody reactive with a human nuclear antigen associated with cell proliferation. Int J Cancer. 1983, 31:13-20. 10.1002/ijc.2910310104

24. Ho DMT, Hsu CY, Ting LT, Chiang H: Histopathology and MIB-1 labeling index predicted recurrence of meningiomas: a proposal of diagnostic criteria for patients with atypical meningioma. Cancer. 2002, 94:1538-1547. 10.1002/cncr.10351

25. Louis DN, Edgerton S, Thor AD, Hedley-Whyte ET: Proliferating cell nuclear antigen and Ki-67 immunohistochemistry in brain tumors: a comparative study. Acta Neuropathol. 1991, 81:675-679. 10.1007/BF00296379

26. Cattoretti G, Becker MH, Key G, et al.: Monoclonal antibodies against recombinant parts of the Ki-67 antigen (MIB 1 and MIB 3) detect proliferating cells in microwave-processed formalin-fixed paraffin sections. J Pathol. 1992, 168:357-363. 10.1002/path.1711680404

27. Abdelzaher E, El-Gendi SM, Yehya A, Gowil AG: Recurrence of benign meningiomas: predictive value of proliferative index, BCL2, p53, hormonal receptors and HER2 expression. Br J Neurosurg. 2011, 25:707-713. $10.3109 / 02688697.2010 .522743$

28. Babu S, Uppin SG, Uppin MS, et al.: Meningiomas: correlation of Ki67 with histological grade. Neurol India. 2011, 59:204-207.

29. Kolles H, Niedermayer I, Schmitt C, et al.: Triple approach for diagnosis and grading of meningiomas: 


\section{Cureus}

histology, morphometry of Ki-67/Feulgen stainings, and cytogenetics. Acta Neurochir. 1995, 137:174-181. 10.1007/BF02187190

30. Abramovich CM, Prayson RA: Histopathologic features and MIB-1 labeling indices in recurrent and nonrecurrent meningiomas. Arch Pathol Lab Med. 1999, 123:793-800. 